\title{
Design, Synthesis and Biological Evaluation of Novel 1, 3, 4-0xadiazole Bearing Pyridine Moiety
}

\author{
Asma D. Ambekari*, Shrinivas K. Mohite \\ Department of Pharmaceutical Chemistry, Rajarambapu College of Pharmacy, Kasegaon, Maharashtra, India \\ Corresponding author E-mail:- asmaambekari1995@gmail.com.
}

\begin{abstract}
Series of novel substituted Synthesis of $\mathrm{N}-\{[5$-(substituted)-1,3,4-oxadiazole-2-yl] carbamothioyl $\}$ derivatives containing 1,3,4-oxadiazole moiety were synthesized by microwave as a green chemistry method and conventional method by using pyridine 3- carboxylic acid as a starting material. The structures of the synthesized compounds were characterized by physicochemical data, IR, Mass spectra and 1HNMR. All the newly synthesized compound screened for their antimicrobial and In-vivo and In-vitro Anti-inflammatory studies. Anti-inflammatory studies revealed that compound $4 \mathrm{f}$ showed significant in-vivo and in-vitro antiinflammatory activity as well potent antimicrobial activity.
\end{abstract}

Keywords : Pyridine 3- carboxylic acid, 1,3,4-oxadiazole, Anti-inflammatory activity.

\section{INTRODUCTION}

It is stable neutrally aromatic molecules and other aromatic molecule are 1,3,4-oxadiazolium captions. They are also referred to be non-aromatic reduced systems 2,5-dihydro-1,3,4-oxadiazole and 2,3,4,5tetrahydro-1,3,4-oxadiazole. Simple 2,5-dialkyl and 2 -alkyl derivatives absorb slightly above $200 \mathrm{~nm}$. It is containing 3 or more conjugated rings having different applications as luminescent compounds.

The azole when attached to a Thiourea functional group forms the building block for pharmaceutical agents. They exhibit a wide spectrum of pharmaceutical activity. In the design of new Thiourea and 1,3,4- oxadiazole derivatives, this novel dual inhibitory activity of enzyme pathway holds promise as anti-inflammatory agent with an improved efficacy and safety profile. It possesses different chemical and biological applications and this nucleus having important in medicinal and organic chemistry. It having number of activities like antioxidant, antimicrobial, anticonvulsant, antitumor, DENV2 inhibitory activity, analgesic etc.

\section{RESULTS AND DISCUSSION}

The starting synthesized compound, 5-(Pyridine-4yl)-1,3,4-oxadiazole-2-amine was prepared by the reaction of pyridine-4-carboxylic acid with hydrazine hydrate and $\mathrm{CNBr}$ in presence of methanol and conc. $\mathrm{H}_{2} \mathrm{SO}_{4}$. and synthesis of substituted benzoyl isothiocyanate was prepared by substituted benzoyl chloride and ammonium thiocyanate in the presence of acetone as a solvent resulted in the formation of the second compound the final desired compound $\mathrm{N}$ \{[5-(substituted)-1,3,4-oxadiazole-2-

1]carbamothioyl\}derivatives was prepared by mixture of 5-(Pyridine-4-yl)-1,3,4-oxadiazole-2-amine and substituted benzoyl isothiocyanate in presence of 
acetone. The experimental procedure is very simple. The process is under green chemistry.

The structures of these synthesized compounds were confirmed by their Physical and spectral analysis. In general, IR spectral data $\left(\mathrm{cm}^{-1}\right)$ revealed bands at 3500-3300 (NH, stretching), 1600-1500 (C=C, stretching), 1300-1100 (C=S stretching), 1900-1700 $(\mathrm{C}=\mathrm{O}), 2800-3300$ ( $\mathrm{C}-\mathrm{H}$ str. of Aromatic ring). In
Nuclear magnetic resonance spectra $(1 \mathrm{H}$ NMR, $\delta$ $\mathrm{ppm})$, the signals of the respective protons at 7.008.02 (Benzene ring, $\mathrm{C}(=\mathrm{O}) \mathrm{N}, \mathrm{NH}$-Secondary amide, 1,3,4- oxadiazole ), 3.49-4.51 (NH-Aromatic). Further, the molecular ion recorded MS $(\mathrm{m} / \mathrm{z}+)[\mathrm{M}+]$ in the mass spectrum is also in agreement with the molecular mass of the compounds.

Table No 1: In vitro anti-inflammatory activity of synthesized compounds measuring the percentage inhibition. (2a-f)

\begin{tabular}{|c|c|c|c|c|}
\hline \multirow[t]{2}{*}{ Compound } & \multicolumn{2}{|c|}{$\begin{array}{l}\% \text { of inhibition of } \\
\text { protein denaturation }\end{array}$} & \multicolumn{2}{|c|}{ Viscosity (cps) } \\
\hline & $\begin{array}{c}50 \mu \\
\mathrm{g} / \\
\mathrm{ml}\end{array}$ & $\begin{array}{l}100 \\
\mu \mathrm{g} / \\
\mathrm{ml}\end{array}$ & $\begin{array}{c}50 \\
\mu \mathrm{g} \\
/ \mathrm{m} \\
1\end{array}$ & $\begin{array}{l}100 \\
\mu \mathrm{g} / \\
\mathrm{ml}\end{array}$ \\
\hline $3 a$ & 66.07 & 68.01 & 89.95 & 87.70 \\
\hline $3 b$ & 66.15 & 65.11 & 86.98 & 86.58 \\
\hline $3 c$ & 64.15 & 64.35 & 86.22 & 86.28 \\
\hline $3 d$ & 61.50 & 66.89 & 85.02 & 87.27 \\
\hline $3 e$ & 42.25 & 70.70 & 85.2 & 88.73 \\
\hline $3 f$ & 71.00 & 75.21 & 88.85 & 90.47 \\
\hline $\begin{array}{c}\text { Standard } \\
\text { (Diclofenac) }\end{array}$ & 72.53 & 75.73 & 89.44 & 90.67 \\
\hline
\end{tabular}

Table 2. In vivo anti-inflammatory activity of synthesized compounds (3f) measuring the percentage inhibition. $(2 a-f)$

\begin{tabular}{|c|c|c|c|c|c|c|c|c|}
\hline \multirow[b]{2}{*}{ Sr. no } & \multirow[b]{2}{*}{ Compound } & \multicolumn{7}{|c|}{$\begin{array}{c}\% \text { inhibition of Paw } \\
\text { Volume }\end{array}$} \\
\hline & & $0 \mathrm{Min}$ & $30 \mathrm{Min}$ & $60 \mathrm{Min}$ & 90 Min & $120 \mathrm{Min}$ & $150 \mathrm{Min}$ & $180 \mathrm{Min}$ \\
\hline 1. & $\begin{array}{l}\text { Control } \\
\text { (Normal) }\end{array}$ & 3.7 & - & - & - & - & - & - \\
\hline
\end{tabular}




\begin{tabular}{|c|c|c|c|c|c|c|c|c|}
\hline 2. & $\begin{array}{c}\text { Standard } \\
\text { (Diclofenac) }\end{array}$ & 0.0 & 13.84 & 22.97 & 27.16 & 39.18 & 52.70 & 60.81 \\
\hline 3. & $2 \mathrm{a}$ & 0.0 & 10.25 & 18.19 & 22.45 & 30.15 & 48.25 & 55.89 \\
\hline 4. & $2 \mathrm{~b}$ & 0.0 & 11.45 & 15.44 & 23.18 & 29.33 & 49.25 & 52.34 \\
\hline 5. & $2 \mathrm{c}$ & 0.0 & 09.18 & 17.33 & 20.14 & 33.15 & 47.14 & 55.92 \\
\hline 6. & $2 \mathrm{~d}$ & 0.0 & 12.17 & 22.44 & 25.12 & 30.11 & 49.00 & 58.90 \\
\hline 7. & $2 \mathrm{e}$ & 0.0 & 13.78 & 21.08 & 24.34 & 34.59 & 51.35 & 61.89 \\
\hline 8. & $2 \mathrm{f}$ & 0.0 & 11.44 & 20.16 & 22.45 & 32.65 & 49.70 & 60.44 \\
\hline
\end{tabular}

The statistical significance of difference across the groups is determined using ANOVA followed by Dunnett's multiple comparisons test. ${ }^{* * * *} \mathrm{p}<0.0001$ [one-way ANOVA, Dunnett's multiple comparisons]. required the reagents were purchased from S.D fine, Research laboratory Mumbai and MERCK laboratory

\section{Pharmacology}

The in vitro anti-inflammatory activity of the test compounds was performed by protein denaturation method. The carrageenan-induced rat paw edema method was used for the evaluation of antiinflammatory activity of oxadiazole derivatives. Animals Wistar rats (100-120gm) of either sex used in this study were purchased from the Animal House of the National Institute of Biosciences, Pune. The animals were maintained under standard laboratory conditions (12 h light/dark cycles at $22 \pm 2 \circ \mathrm{C}$ ), humidity $45-55 \%$ and fed standard rodent pellets (National Institute of Biosciences, Pune, Maharashtra) and water. The protocol and procedure was approved by the CPCSEA. ${ }^{[1]}$.

\section{Experimental}

Chemicals and solvents were procured from commercial sources, purified and dried using standard procedures from literature whenever
Mumbai. The melting points $\left({ }^{\circ} \mathrm{C}\right)$ of synthesized compound were determined in open capillary tube method and are uncorrected. Thin layer chromatography was used confirmation of reaction and the purity of the intermediate and the final compounds by applying a single spot on TLC plate ( silica gel G ) using various solvents such as toluene, acetone, ethanol system. TLC plates were visualized under iodine chamber. IR spectra were recorded on ATR JASCO FTIR-4600. H1NMR spectra were performed in DMSO solution using Bruker $300 \mathrm{MHz}$ and their chemical shift are reported in $\delta$ unit with respect to TMS as internal standard. Mass spectra were recorded on Pe sciex (model no. API 2000) software analyst 1.4.2 mode: Q1MS Q1/AUTO INJECTION.

\subsection{General procedure for the synthesis of 5- (Pyridine-4-yl)-1,3,4-oxadiazole-2-amine :}

Methyl carboxylate was prepared by using 0.01 mole of pyridine-4-carboxylic acid in $35 \mathrm{ml}$ methanol. Carboxylic acid is esterified with methanol, further 
reaction is processed by refluxing the mixture for 5-6 hours by adding few drops of $\mathrm{H}_{2} \mathrm{SO}_{4}$ as catalyst. After completion of reaction solid was formed which was used for next step for the preparation of substituted carbohydrazide. The mixture of above compound $(0.01 \mathrm{~mol})$ and $4 \mathrm{ml} 99 \%$ hydrazine hydrate was refluxed for 4-5 hours. After completion of reaction checked by TLC and solid precipitate was dried and recrystallize from methanol. The mixture of above substituted carbohydrazide $(0.01 \mathrm{~mol})$ in $20 \mathrm{ml}$ methanol and add cynogen bromide $(0.01 \mathrm{~mol})$ this reaction mixture was stirred and refluxed at $55-56^{\circ} \mathrm{C}$ for 2 hour, after completion of reaction checked by TLC. The solution was cooled and neutralized with NAHCO3. The solid precipitate was washed, dried and recrystallize from ethanol.

General procedure for the synthesis of substituted benzoyl isothiocyanate :
A solution of substituted benzoyl chloride $(10 \mathrm{mmol})$ in acetone $(50 \mathrm{ml})$ was added dropwise to ammonium thiocyanate $(10 \mathrm{mmol})$ in absolute acetone $(30 \mathrm{ml})$. the reaction mixture was heated $\left(50^{\circ} \mathrm{C}\right)$ under refluxed for $30 \mathrm{~min}$. after completion of reaction checked by TLC. The reaction mixture was cooled to room temperature and the formed precipitate $(\mathrm{NH} 4 \mathrm{Cl})$ was filtered off. To the freshly prepared solution of aroyl isothiocyanate derivative.

General procedure for the synthesis of $\mathrm{N}-\{[5-$ (substituted)-1,3,4-oxadiazole-2-yl]carbamothioyl\} derivatives:

A solution of 5-(pyridine-4-yl)-1,3,4-oxadiazole-2amine $(10 \mathrm{mmol})$ in acetone $(10 \mathrm{ml})$ was added and the resulting mixture was stirred with refluxed for 23hr. after completion of reaction checked by TLC. The solid prod was washed with water and purified by washing with ethanol absolute.

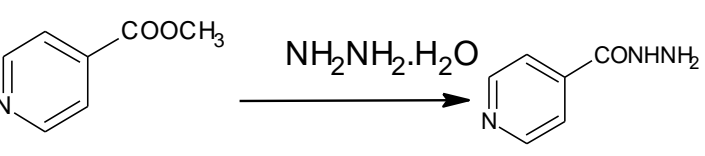

methyl

pyridine-4-carboxylate

pyridine-4-carboxylic acid

$$
+\underset{\text { Methanol }}{\mathrm{CH}_{3} \mathrm{OH} \stackrel{\text { Conc. } \mathrm{H}_{2} \mathrm{SO}_{4}}{\longrightarrow}}
$$<smiles>O=C(P)Cl</smiles>

Aroyl Chloride

$(1 a-f)$ pyridine-4 4 carbohydrazid

$$
\text { e }
$$<smiles></smiles>

5-(pyridin-4-yl)-1,3,4oxadiazol-2-amine

Substituted[5-(pyridin-4-yl)-1,3,4-oxadiazol-2-yl]benzamide derivative

$\mathrm{R}=$ Where

\begin{tabular}{|l|l|l|l|}
\hline $\mathrm{R}$ & & $\mathrm{R}$ & \\
\hline
\end{tabular}

$(2 a-f)$

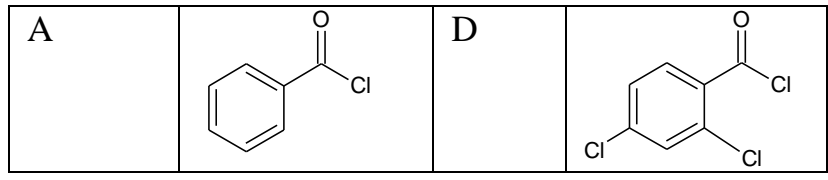




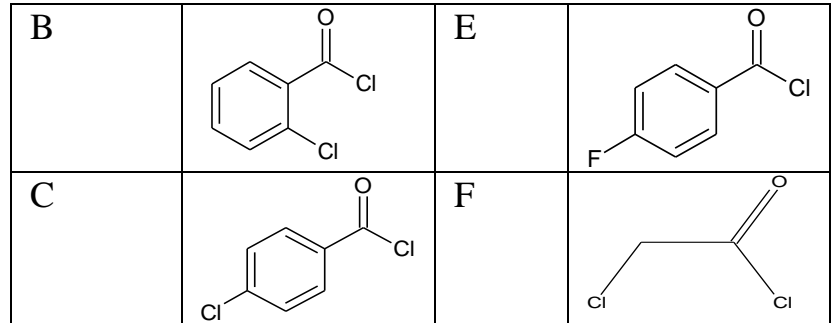

(2a). $\quad N$-\{[5-(pyridine-4-yl)1,3,4-oxadiazole-2-yl] carbamothioyl\}benzamide:

This compound isolated as brown colour solid with 76\% yield, m.p. $134-136{ }^{\circ} \mathrm{C}$; IR $\left(\mathrm{KBr} \mathrm{cm}^{-1}\right): 3500$ ( $\mathrm{NH}$ - str.), 1718 ( $\mathrm{C}=\mathrm{O}$ ), 1376 ( $\mathrm{C}=\mathrm{S}$ ), 1509 (C=C str.), 3262 (C-H str. of Aromatic ring), 1660 ( $\mathrm{C}=\mathrm{N}$ str.), 1263 (C-C) : 1H NMR (400 MHz, DMSO-d6) : 7.46$7.52(5 \mathrm{H}$, Benzene ring, $\mathrm{C}(=\mathrm{O}) \mathrm{N})$; 7.63-7.69 $(4 \mathrm{H}, 4-$ Pyridine, 1,3,4-oxadiazole), 7.957 (1H, NH Secondary amide), $4.00(1 \mathrm{H}, \mathrm{NH}$ Aromatic) : MS (m/z+) [M+] 324; For $\mathrm{C}_{15} \mathrm{H}_{11} \mathrm{~N}_{5} \mathrm{O}_{2} \mathrm{~S}$.

(2d). 2,4-dichloro-N-\{[5-(pyridine-4-yl)1,3,4oxadiazole-2-yl] carbamothioyl\}benzamide:

This compound isolated as brown colour solid with 74\% yield, m.p. $166-168^{\circ} \mathrm{C}$; IR ( $\left.\mathrm{KBr} \mathrm{cm}^{-1}\right): 3407$ ( $\mathrm{NH}$ str.), 1670 ( $\mathrm{C}=\mathrm{C}$ str.), 1105 ( $\mathrm{C}=\mathrm{S}$ ), 1922 ( $\mathrm{C}=\mathrm{O}$ str.), 2981 ( C-H str. of Aromatic ring), 1201 (C-C), 1536 (C=N str.), $763(\mathrm{C}-\mathrm{Cl})$ : 1H NMR (400 MHz, DMSOd6) : 7.46-7.51 ( $3 \mathrm{H}$, Benzene ring, $\mathrm{C}(=\mathrm{O}) \mathrm{N})$; 7.587.93 ( 4H, 4-Pyridine, 1,3,4-Oxadiazole), $7.96(1 \mathrm{H}$, NH Secondary amide), 3.809 (1H, NH Aromatic) : MS $(\mathrm{m} / \mathrm{z}+)[\mathrm{M}+]$ 394; For $\mathrm{C}_{15} \mathrm{H}_{9} \mathrm{Cl}_{2} \mathrm{~N}_{5} \mathrm{O}_{2} \mathrm{~S}$.

\section{(2e). 4-fluro -N-\{[5-(pyridine-4-yl)-1,3,4-oxadiazole-} 2-yl] carbamothioyl\}benzamide:

This compound isolated as brown colour solid with 82\% m.p. 112-114 ${ }^{\circ} \mathrm{C}$; IR ( $\left.\mathrm{KBr} \mathrm{cm}^{-1}\right)$ : 3585 ( $\mathrm{NH}$ str.), 1600 ( C=C str.), 1160 ( C=S), 1882 (C=O), 2873 ( C-H str. of Aromatic), 1203 (C-C), 1533 (C=N str.), 811 (CF) : 1H NMR (400 MHz, DMSO-d6) : 7.28- $7.50(4 \mathrm{H}$,
Benzene ring, $\mathrm{C}(=\mathrm{O}) \mathrm{N}, \mathrm{F}$ ), 7.95-8.00 ( $4 \mathrm{H}$, 4-Pyridine, 1,3,4-Oxadiazole), 8.027 (1H-NH Secondary amide), $3.499(1 \mathrm{H}, \mathrm{NH}$ Aromatic) : MS (m/z+) [M+] 344; For; $\mathrm{C}_{15} \mathrm{H}_{10} \mathrm{FN}_{5} \mathrm{O}_{2} \mathrm{~S}$.

(2f). 2-chloro-N-\{[5-(pyridin-4-yl)-1,3,4-oxadiazol-2yl] carbamothioyl\}acetamide:

This compound isolated as brown colour solid with 80\%.m.p 126-128 $\mathrm{C}$; IR ( $\left.\mathrm{KBr} \mathrm{cm}^{-1}\right)$ : 3345 (NH str.), 1577 (C=C str.), 1295 (C=S), 1722 (C=O), 1508 (C=N str.), 719 (C-Cl) : 1H NMR (400 MHz, DMSO-d6) : 7.40-7.52 ( 4H, 4-Pyridine, 1,3,4-Oxadiazole), 7.94 (1H, NH Secondary amide), 4.51 (1H, NH-Aromatic), $3.42(1 \mathrm{H}, \mathrm{Cl}): \mathrm{MS}(\mathrm{m} / \mathrm{z}+)[\mathrm{M}+]$ 296; For $\mathrm{C}_{10} \mathrm{H}_{8} \mathrm{ClN}_{5} \mathrm{O}_{2} \mathrm{~S}$.

\section{Anti-inflammatory activity:}

a) In vitro Anti-inflammatory evaluation

The compounds have been bought from research lab, Mumbai, India. And the solvent were purified by distillation process. The test of 1,3,4-oxadaizole derivatives were synthesized in our laboratory. DMSO as a solvent Diclofenac sodium $(50 \mu \mathrm{g} / \mathrm{ml})$ as a standard $50 \mu \mathrm{g} / \mathrm{ml}, 100 \mu \mathrm{g} / \mathrm{ml}$ as test compound UV spectrophotometer instrument for absorbance.

Method: Synthesized compound's In vitro antiinflammatory action by protein denaturation method. $(2 a-f)$

The sample mixture $(10 \mathrm{ml})$ consist of $0.4 \mathrm{ml}$ of albumin egg (from new egg), $0.6 \mathrm{ml}$ of phosphate buffered solution ( $\mathrm{pH}$ 6.4) and $4 \mathrm{ml}$ of changing concentration of test samples so that final concentration become $50 \mu \mathrm{g} / \mathrm{ml}, 100 \mu \mathrm{g} / \mathrm{ml}$. same volume of DMSO act as control. Then the sample incubation of compounds $\left(7^{\circ} \mathrm{C} \pm 2\right.$ ) for $15-20$ minutes. and then heat for $5 \mathrm{~min}$ at $700 \mathrm{C}$. After cooling sample, its absorption was recorded at 660nm (JASCO UV Spectrophotometer) by using a blank carrier. Their viscosity was determined with the support of 
Ostwald viscometer. Sodium Diclofenac at last level of $50 \mu \mathrm{g} / \mathrm{ml}, 100 \mu \mathrm{g} / \mathrm{ml}$ was used for the conventional medicine and similar treatment for absorption and viscosity determination. by making use of the corresponding formula, the percent protein cell lysis inhibition calculated.

\section{Absorbance of control - Absorbance of test}

$\%$ inhibition protein denaturation :

Absorbance of control

a) In vivo- Anti-inflammatory evaluation of synthesized compound.

Animals Used for anti-inflammatory activity

Animals Wistar rats (100-120gm) of either sex was purchased from the National Biomedical Research center Animal House in Pune. The animals the normal experimental terms (12 hours) were preserved light/dark cycles at $22 \pm 2$ ?C), humidity 45 $55 \%$ and feeding normal pellets for animals (National Institute of Biosciences, Pune, Maharashtra) and water. The protocol and procedure was approved by the CPCSE (Reg.No. 1290/PO/Re/S/09/CPCSEA $16 / 03 / 19$.)

\section{In vivo- Anti-Inflammatory Activity. (2a-f)}

Anti-inflammatory activity was assessed by carrageenan-induced paw edema test using group of Wistar rats weighing 100-120gm each and 2 rats per group as standard, test and control. In each rat, the hind paw edema was caused by $0.1 \mathrm{~mL}$ of carrageenan suspension (1.0 percent $\mathrm{w} / \mathrm{v}$ in 0.9 percent saline) sub-plantar injection $1 \mathrm{~h}$ going to follow oral administration sample compounds and conventional drug. The linear circumference of the paw was evaluated immediately prior to injection, using the cotton thread technique at an average of $30 \mathrm{~min}$ for 4 h. Anti-inflammatory activity is determined by assessing the edema size decrease and determining the percentage of edema inhibition. An indication of anti-inflammatory activity is a decrease in edema relative to control and an increase in percent inhibition in the processed groups. The mean \% inhibition of Diclofenac and tested compound at 25 mg kg-1 concentration Control was compared and repeated measures ANOVA with Dunnet's test.

\section{b) Antimicrobial activity}

The filter paper disc method was performed in nutrient agar for bacterial and Sabraud's agar for fungi. These agar media were inoculated with $0.5 \mathrm{~mL}$ of the $24 \mathrm{hr}$ liquid culture. Filter paper disc $(5 \mathrm{~mm}$ diameter) saturated with each compound solution $(500 \mu \mathrm{g} / \mathrm{mL}$ of DMSO) were placed on indicated agar media. The incubation time was $48 \mathrm{hr}$ at $36^{\circ} \mathrm{c}$. Amoxicillin (10mg/mL of DMSO) was used as standard against Fluconazole (10mg/ML of DMSO) was used as standard against fungi. The diameter of inhibition zone in $\mathrm{mm}$ were measured and recorded in Tables 3 and 4 as antibacterial and antifungal, respectively. ${ }^{[2,7]}$

Table No. 3 Antimicrobial activity of the synthesis compounds (a-f) against Staphylococcus aureus, Bacillus subtilis, Escherichia coli, Pseudomonas aeruginosa, Candida albicans.

Zone of inhibition (mm)

Compounds

\begin{tabular}{ccccc}
$\begin{array}{c}\text { Staphylococcus } \\
\text { aureus }\end{array}$ & $\begin{array}{c}\text { Bacillus } \\
\text { subtilis }\end{array}$ & $\begin{array}{c}\text { Escherichia } \\
\text { coli }\end{array}$ & $\begin{array}{c}\text { Pseudomonas } \\
\text { aeruginosa }\end{array}$ & $\begin{array}{c}\text { Candida } \\
\text { albicans }\end{array}$ \\
\hline
\end{tabular}




\begin{tabular}{cccccc}
\hline $2 \mathrm{a}$ & ++ & +++ & ++ & - & ++ \\
$2 \mathrm{~b}$ & - & ++ & +++ & + & - \\
$2 \mathrm{c}$ & + & ++ & ++ & + & + \\
$2 \mathrm{~d}$ & ++ & - & - & ++ & - \\
$2 \mathrm{e}$ & - & + & ++ & ++ & - \\
$\mathbf{2 f}$ & ++ & + & ++ & + & ++ \\
Amoxicillin & +++ & - & - & - & ++ \\
Fluconazole & - & - & - & ++ \\
\hline
\end{tabular}

${ }^{*}$ Highly active $=+++($ Inhibition zone $>12$ $\mathrm{mm}$ )

Moderately active $=++$ (Inhibition zone 9-12 $\mathrm{mm}$ )

Slightly active $=+($ Inhibition zone $6-9 \mathrm{~mm})$ Inactive $=-($ Inhibition zone $<6 \mathrm{~mm})$

\section{III.CONCLUSION}

This investigation proposes, economical, cheaper and useful method for the $\mathrm{N}$-\{[5-(substituted)-1,3,4oxadiazole-2-yl] carbamothioyl\} derivatives possessing anti-inflammatory , antimicrobial properties. Exhaustive pharmacological studies have been conducted with the 1, 3, 4-oxadiazole derivative. The 5-position are an extremely important site of molecular modification, which play a dominant role in determining the pharmacological activates of 1,3 , 4- oxadiazole derivatives. This new class of heterocycles, exhibit a significant anti-inflammatory activity. Hence, it can concluded that, this new class of compounds certainly holds a greater promise in discovering a potent anti-inflammatory agent. The compound $2 \mathrm{f}$ shows potent antimicrobial, in vivo anti-inflammatory and in vitro anti-inflammatory activity.

\section{ACKNOWLEDGEMENT}

I wish to express my sincere thanks to Vice Principal Prof. Dr. S. K. Mohite for providing me all necessary facilities and valuable guidance extended to me. I also thanks to Principal Dr. C. S. Magdum for their encouragement and support.

I also place on record, my sense of gratitude to one and all who, directly or indirectly have lent their helping hand in this research.

\section{REFERENCES}

[1]. Allison MC, Howatson AG, Torrance CJ, Lee FD, Russell IG., 1992. N Engl J Med. 327, 749754.

[2]. Bauer AW, Kirby W.W.M, Sherris J.C, Turck M., Clin Am. J., 1996. Pathol. 45, 493.

[3]. Bekhit AA, Tarek AA., 2004. Bioorg Med Chem.12, 1935-1945.

[4]. Bhansali S, Kulkarni V., 2015. Der Pharma Chemica. 7(1): 156.

[5]. Chopade A, Sayyad F, Naikwade N., 2014. Pharmacol Rep. 353-362.

[6]. Chopade A, Sayyad F., 2015. Phytother Res Int. 29, 1202-1210.

[7]. Kalyoncuoglu N, Rollas S, Sur-Altiner D, Yegenoglu, Ang O., 1992. Pharmazie, 47, 769.

[8]. Raju G, Swathi K, Padma K, Sravani Y, Rao N., 2015. Asian J. Pharm. Sci. 3(1), 20-30.

[9]. Ranian K, Parmar S, Salzman S., 1998. J. Pharm. Sci. 78(12), 999-1002.

[10]. Rathore A, Sudhakar R, Ahsan M, Ali A, Subbarao N, Jadav S, Umar S, Shahar Yar M., 2016. Bioorg Med Chem. 66, 1-35. 
[11]. Ravindra KC, Vagdevi HM, Vaidya VP, Padmashali B., 2006. Indian J Chem B. 45, 2506-2511.

[12]. Singh AK, Parthsarthy R, Lohani M., 2012. J Chem Pharm Res. 4, 779-782.

[13]. Sondhi M, Dinodia M, Singh J, Rani R., 2007. Curr Bioact Compd. 3, 91-108.

[14]. Talley JJ, Brown DL, Carter JS, Graneto MJ, Koboldt CM, Masferrer JL, Perkins WE, Rogers RS, Shaffer AF, Zhang YY, Zweifel BS, Seibert K., 2000. J Med Chem. 43, 775-777.

[15]. Vishwanathan B, B.M. Gurupadayya., 2015. Int. J. Pharm. 2, 41-51.

\section{Cite this article as :}

Asma D. Ambekari, Shrinivas K. Mohite, "Design, Synthesis and Biological Evaluation of Novel 1, 3, 4Oxadiazole Bearing Pyridine Moiety", International Journal of Scientific Research in Science and Technology (IJSRST), Online ISSN : 2395-602X, Print ISSN : 2395-6011, Volume 6 Issue 5, pp. 300-307, September-October 2019. Available at doi : https://doi.org/10.32628/IJSRST196535 Journal URL : http://ijsrst.com/IJSRST196535 